\title{
Conventional versus electrical enhanced oil recovery: a review
}

\author{
Muhammad Mohsin Rehman • Mahmoud Meribout
}

Received: 14 March 2012/Accepted: 12 August 2012/Published online: 28 September 2012

(C) The Author(s) 2012. This article is published with open access at Springerlink.com

\begin{abstract}
This paper presents a critical and an analytical view of some unconventional EOR techniques. This includes microwave heating, ultrasonic stimulations, direct current (DC) heating and induction heating. It also demonstrates that for some specific reservoirs scenarios, some of these unconventional techniques may provide more efficient results, in terms of recovery rate, over conventional techniques in some specific reservoir scenarios. It also discusses two widely investigated electrical techniques i.e., microwave heating and ultrasonic stimulations and provides two practical setups for field-scale implementation. Different conventional and electrical EOR techniques are also compared in terms of their application suitability and limitations.
\end{abstract}

Keywords Enhanced oil recovery $\cdot$ EOR .

Conventional EOR · Electrical heating .

Microwaves EOR

\section{Introduction}

Oil and gas constitute the main resources for the development of many countries in the world (Butt 2001). On the other hand, because of the industrialization, oil consumption is increasing which motivated oil producing countries to optimize their production. However, most of easy oil has been already extracted, leaving a non-negligible quantity of highly viscous trapped oil in the reservoirs. This requires the usage of what is commonly known by enhanced oil

M. M. Rehman $(\bowtie) \cdot$ M. Meribout

Department of Electrical Engineering, The Petroleum Institute, Abu Dhabi, United Arab Emirates

e-mail: mrehman@pi.ac.ae recovery (EOR) techniques. More specifically, when a well is drilled in a hydrocarbon depleted area for primary recovery, the oil starts flowing towards the producing well because of the pressure difference between the bottom of the producing well and the reservoir leading to oil recovery of $5-25 \%$ of the original oil in place. Pumps are installed to maintain the production when the pressure of the reservoir is reduced (Andrei et al. 2010). After passing this stage, hydrocarbon gases are injected in the reservoirs so as to raise the pressure but these gases are a huge economic burden on oil companies. After the primary recovery, some other methods to increase the pressure inside the reservoirs are adopted including hydrocarbon gas injection, water flooding, $\mathrm{CO}_{2}$ injection, chemical flooding etc. This stage of oil recovery is termed as secondary recovery (Green and Willhite 1998). For instance, currently in United Arab Emirates (UAE), Abu Dhabi Company for Onshore Oil Operations (ADCO) is using hydrocarbon gases in $\mathrm{Abu}$ Dhabi oil reservoirs. On receiving successful results from the pilot project of $\mathrm{CO}_{2}$ injection, the company plans to use $\mathrm{CO}_{2}$ injection as a replacement for hydrocarbon gas injection into the reservoirs to increase the pressure (Saadawi et al. 2011). Besides these conventional EOR methods, some non-conventional e.g., electrical techniques are also being investigated to enhance the production of oil with high efficiency, low cost and in less time. Electrical heating methods are better in terms of the depth of the reservoir and controlling the heat loss (Acar 2007). In addition, they can achieve higher efficiency in heterogeneous reservoir environment as compared to conventional steam flooding (Carrizales and Lake 2009). Another benefit of using electrical heating is that the energy can be applied directly into the area of interest (Chakma and Jha 1992). Workman was the first to propose electro-EOR as a suitable candidate (Workman 1930). The use of high density 
DC electric current for EOR has also been proposed by many researchers (Bruninga 1957; Sarapuu 1957). In addition, alternating current was demonstrated to a good candidate to heat oil reservoirs and in turn decrease their viscosity resulting in improved oil production (Gill 1970; Crowson 1971). Numerous lab experiments have been conducted by many researchers on the use of electro osmosis and suggesting it as a good candidate for EOR (Amba et al. 1964; Chilingar et al. 1968; George et al. 1997).

Electromagnetic heating has been investigated and proposed as a potential candidate for near well bore heating (George et al. 1997). These techniques especially microwave heating can also be applied to the shallow reservoirs which are not suitable for chemical or gas injection processes.

This paper explores the technical feasibility and economic potential of employing the electrically EOR schemes. Following the introduction is the section discussing briefly the conventional EOR techniques which are actually being employed. Next section elaborates the term electrical heating with its types followed by some discussions on few related setups commonly used in electricalbased EOR. In addition, ultrasonic stimulation technique is also briefly discussed. The next section outlines the differences between the electrical and conventional-based EOR techniques. Finally the future of the unconventional EOR and some related research areas are discussed.

\section{Conventional EOR techniques}

EOR can be applied in one of the three following methods:

- Primary technique

- Secondary technique

- Tertiary recovery

After oil discovery, a primary recovery undergoes a period of oil production based on natural reservoir energy or pressure. EOR as a secondary recovery technique is used at the stage when oil cannot be extracted if the extraction relies solely on the natural reservoir pressure. Consequently, an introduction of energy into the reservoir is usually required at this stage of recovery. In conventional oil recovery, the most popular method used for secondary recovery is water flooding. Hence, the water is flooded through the reservoir so as it may push the remaining oil towards the production well. Nevertheless, this method may induce some serious limitations as well. For instance, formation damage may take place based on the reaction between the injected water and the formation water. In addition, this technique may induce a corrosion of the subsurface electro-mechanic devices (e.g., pumps, valves, and sensors). In addition, the heterogeneous reservoir rocks sometimes make it hard for water to put pressure on oil.
This triggers the need to use a more powerful recovery technique, namely, the tertiary recovery technique, which is referred in this paper as EOR. Commonly, the following EOR techniques are employed in the oil fields (Stevens et al. 1998).

\section{- Thermal EOR \\ - $\mathrm{CO}_{2}$-EOR \\ - Other gas EOR \\ - Chemical EOR}

In thermal EOR, steam is injected into the reservoir to reduce the viscosity of the heavy oil and/or vaporize the oil so as it may flow and can be extracted easily. Thermalbased EOR also involves the in-situ combustion entailing heat generation within the reservoir containing low gravity oil. Increased heat within the reservoir reduces the surface tension and increases the permeability of oil. Thermal EOR is usually applied in case of Shallow reservoirs (which are less than 3,000 feet deep) of heavy crude oil. In addition, this technique is also mainly applied to large fields which can provide high return on investment. $\mathrm{CO}_{2}$-based EOR is being used widely and also depends upon economic availability of $\mathrm{CO}_{2}$ from natural and/or industrial resources. This method has worldwide demonstrated its efficiency, where for instance in 2006, about $37 \%$ of oil production in the US was contributed by $\mathrm{CO}_{2}$-based EOR.

Other gas-based EOR includes the insertion of hydrocarbon or nitrogen gases into oil reservoirs. This technique is widely used in oil fields for gas cycling, reservoir pressure maintenance and gas lift. Financially, it is normally cheaper than $\mathrm{CO}_{2}$-based EOR with the added advantage that it is non-corrosive as well (Stevens et al. 1998).

Usually gas-based EOR has two types of injections:

- Miscible injection, in which the injected gas is dissolved in the oil inside the reservoir and the underlying oil/gas solution starts flowing towards the production well as a result of a decrease in the viscosity of oil. Mainly miscible method is adopted to reduce the interfacial tension for improvement in displacement efficiency. But miscibility can only be achieved at specified temperature and pressure conditions in the presence of a specific chemical composition. It is economically expensive and can only be carried out with justified reasons. Safety issues are also of paramount nature in this case.

- Immiscible injection, in which the injected fluid does not mix up with the oil and water completely because of the characterization of oil. It is just absorbed inside the oil and water and starts building pressure which in turn tends to the movement of oil blobs lying at different places. These oil blobs are mixed with each other and start flowing towards the production well. 
It is worth noting that the main consideration in the two aforementioned injection methods is that miscible injection is usually carried out for fractured reservoirs while immiscible injection is done for non-fractured or limited fracture reservoirs. For instance, for a reservoir having $1,000 \mathrm{psi}$ fracture pressure, miscible injection of 1,200 psi cannot be performed as it will fracture the reservoir. Instead, immiscible fluid would be better in this case.

A liquid-based tertiary recovery technique consists of inject $\mathrm{CO}_{2}$ intermittently (e.g., days or months, depending upon the reservoir geology) water into the reservoir. This process is termed as water alternating gas (WAG) flooding as shown in Fig. 1. Brine is injected in the formation in order to push the supercritical $\mathrm{CO}_{2}$ further into the depth of reservoir in oil rich zones. In this processes, supercritical $\mathrm{CO}_{2}$ and brine are injected alternately. Although it is one of the best available conventional EOR techniques, it is suffering from the low viscosity of $\mathrm{CO}_{2}$. This is because $\mathrm{CO}_{2}$ forms viscous fingering inside the reservoir resulting in reduced recovery.
In some situations, chemical injection is also used in oil fields to enhance oil production by reducing the surface tension of the formation liquid. However, it is technologically complex to implement since it requires relatively complex and expensive equipment. Though, it may be a good alternative in case there is much oil trapped in the reservoir, within which the acid content is high.

Alkaline flooding is limited in application scope as it can only be done for the reservoir in which acid content is high, alcoholic flooding has not been field tested yet. Surfactant flooding is used to reduce the surface tension of the formation liquid, which results in high chemical losses.

As for the recovery time, the effectiveness of using one or another conventional EOR technique depends upon the heterogeneity of the reservoir. For instance, in case the formation is permeable and contains a low viscous crude oil, the recovery time will also be faster than in case of less permeable reservoir containing high viscosity crude oil. Since it is difficult to generalize the recovery efficiency of a particular EOR technique, therefore a comparison of different techniques is provided based on 117 oil field

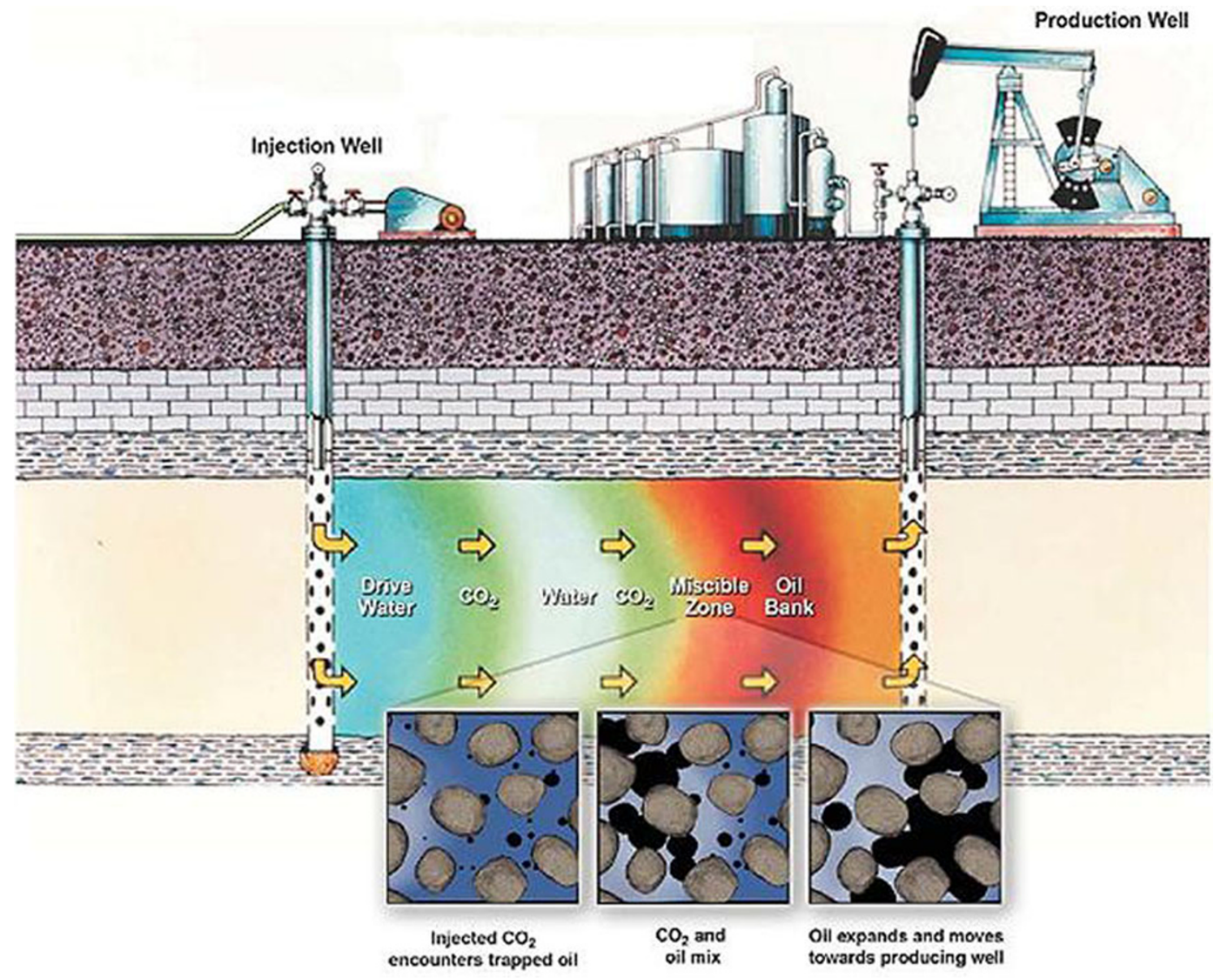

Fig. $1 \mathrm{CO}_{2}$ flooding (WAG) (Carter 2011)

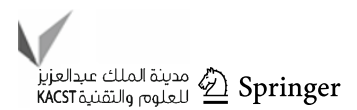


experiments. Distribution of the types of EOR techniques employed along with the oil recovery from each of these techniques is shown in Table 1(Hammershaimb et al. 1983; Kuuskraa et al. 1983; Teknica 2001).

\section{Electrical EOR techniques}

In the literature, it has been found that the usage of the aforementioned conventional techniques for long term production of heavy oil, usually damages the formation (Baptist 1960; Zhou et al. 1996). This is mainly due to the deposition of paraffin near the well bore and incursion of outside liquids and solids for various types of production operations. Paraffin deposition may also reduce the formation permeability. In addition, these thermal oil recovery techniques may also force the deposited paraffin into the formation resulting in pore throat plugging which may lead to production loss (Bailey et al. 2001).

Another alternative/complementary technique to the conventional EOR techniques is the electrical-based EOR (EEOR). Hence, using some electrical means (e.g., sound waves, RF waves, inductive heating, DC heating etc.), oil can be recovered from the reservoirs at much low cost and with enhanced efficiency as compared to the above discussed conventional EOR methods. Basic function of EEOR process is to increase the mobility of the oil by reducing its viscosity which in turn would help the oil to easily move towards the production well. This is because the electrical energy supplied to the reservoir will either raise the temperature of the oil or create vibrations in the hydrocarbon molecules.

Based on the frequency of electrical current being used, the electric heating methods can be divided into three main categories. Low frequency electric current is best suited for Ohmic or resistive heating while high frequency electric current can be used for microwaves heating methods. On the contrary, for inductive heating, a range of low and medium frequency electric currents can be used depending on the energy availability (Hascakir et al. 2008).

\section{Low frequency heating}

Low frequency electric reservoir heating is also called Ohmic/Joule heating because in this method the electric current passes through the formation and due to power dissipation, heat is produced which in turn heats up the reservoir. This method can be employed by using two oil wells; one as anode and the other as cathode, a potential difference is provided between these two electrodes and a current is allowed to pass through the formation which is having salty water and can conduct electricity fairly (Sierra et al. 2001). It can suitably be employed in different types of reservoirs having different formation depth, formation porosity and permeability, temperature, pressure and thickness etc. (Oliveira et al. 2009).

The electrical conductivity in the formation can be found by the following expression, which shows how far the heating effect will reach and is also called as Archie and Humble's relation (Sierra et al. 2001) and (Islam and Chilingarian 1995):

$R=0.62 R_{\mathrm{w}} / \phi^{2.15} S_{\mathrm{w}}^{2}$

Where $\Phi$ is porosity of the reservoir, $S_{\mathrm{w}}$ is the proportion of reservoir containing water or water saturation and $R_{\mathrm{w}}$ is the resistivity of brine and is given in ohm-meters and shows the dependence of water resistivity on temperature and is defined as:

$R_{\mathrm{w}}=R_{\mathrm{wt}}\left(T_{\mathrm{r}}-251.65\right) /(T-251.65)$

In the above expression, $T$ is the initial temperature of reservoir in Kelvin while $T_{\mathrm{r}}$ is the reservoir temperature after passage of electric current through it. A view of the low frequency heating procedure is shown in Fig. 2.

One limitation of this method is that the amount of heat dissipated is reduced as the quantity of water decreases and in case the majority of water is converted into steam as a result of heating. One suggestion is to use water injection along with this method (Harvey et al. 1979). According to Akfhampour (1985), commercially available mineral insulated (MI) cables can be used for producing heat. In this method brine is not needed to conduct electricity instead, two conductors insulated with graphite and polymer are used for the purpose. With the rise of temperature, the mineral resistance also increases which in turn increases the temperature even more. A self-regulating mechanism is achieved which prevents from overheating. These heater wires are available in lengths ranging from 300 to $1,000 \mathrm{~m}$ and are suitable for use in horizontal and shallow reservoirs for heating purpose. The source required for this purpose is $480 \mathrm{~V} \mathrm{AC}$.

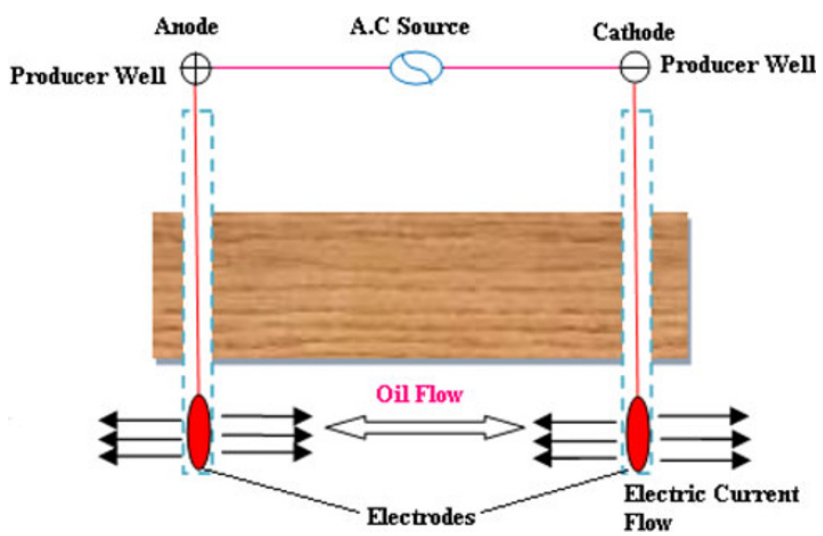

Fig. 2 Low frequency heating (Ohmic heating) 


\section{Inductive heating}

Electric source impressed upon at its edges produces alternating electric and magnetic fields causing eddy as well as displacement currents to flow through the surrounding materials. Eddy currents flow through the metallic materials producing heat and raising temperature while displacement currents, also called radio frequency (RF) waves, are involved more in the dielectric materials. Both of these eddy currents as well as displacement currents flow depend upon the dielectric loss factor and resistivity distribution of the reservoir.

A study conducted by Fisher (2007) on some specific reservoirs showed that in oil shale the desired temperature was $550{ }^{\circ} \mathrm{C}$ (for this case) and the input heat required was $153 \mathrm{kWh} /$ ton and in oil sand the maximum temperature required was $300{ }^{\circ} \mathrm{C}$ and input heat requirement was $123 \mathrm{kWh} /$ ton.

In case of induction heating, a number of inductors are normally installed at the bottom of production tubing facing the production zone. Production tubing acts as inductively heated source to radiate heat inside the production zone as shown in the Fig. 3 below. Mostly inductive heating is employed for near well bore heating in vertical wells. The inductive tool can be installed near the heavy formation resulting in increased oil recovery because of reduction of viscosity of formation oil. A proposed configuration for induction heating is shown in Fig. 3 (Vermeulen and McGee 2000).

An inductor is attached to the production tubing opposing the production zone. Production casing is utilized as the inductively heated element to heat the surrounding of well bore. Bahrain Petroleum Company conducted the Induction heating with a power of 5-8 KW at Bahrain oil fields in 1998-2001 and as a result, the production output was tripled (Sierra et al. 2001). In addition, Inductive heating also raises the temperature of rocks and other inorganic materials present in the reservoir. The heat transfer from electromagnetic energy source to the porous rock media can be given by the Energy equation. Increase in temperature can be calculated as follows (Hascakir et al. 2008):

$\rho c_{\rho} \frac{\partial T}{\partial t}+\rho_{\mathrm{f}} c_{\rho \mathrm{f}} \vec{v}_{\mathrm{f}} \vec{\nabla} T=\vec{\nabla} \cdot\left(\lambda_{\mathrm{c}} \vec{\nabla} T\right)+P$

Where $c_{\rho}$ and $\lambda_{\mathrm{c}}$ represent the density, specific heat capacity and thermal conductivity of the medium respectively $\rho_{\mathrm{f}}, c_{\rho \mathrm{f}}$ and $\vec{v}_{\mathrm{f}}$ are the density, specific heat capacity and superficial velocity of the fluid phase. $\mathrm{P}$ is the electromagnetic power dissipated per unit of volume and is a function of the electric field, $\vec{E}$ and the effective conductivity $\sigma$ of the medium and it is given by:

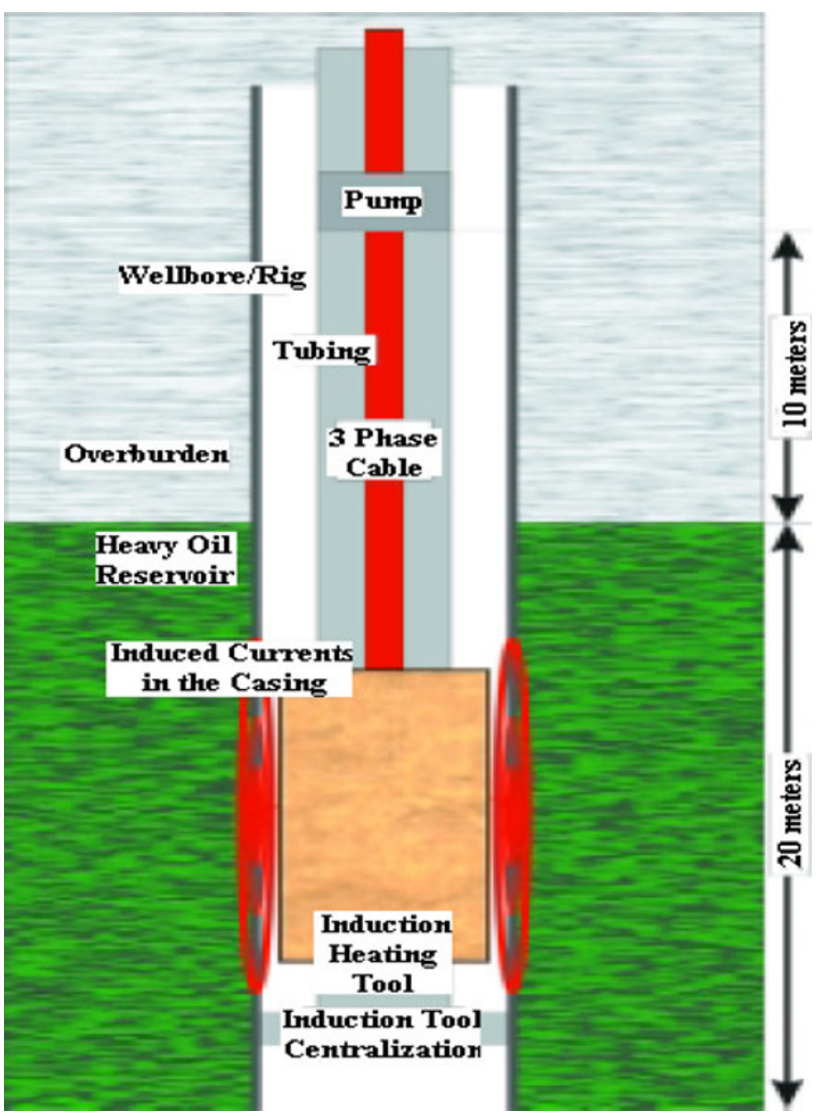

Fig. 3 Configuration of wellbore for induction heating (Vermeulen and McGee 2000)

$P=\frac{\sigma+\omega \varepsilon \tan \delta}{2}|\vec{E}|^{2}$

A comparison of steam injection and inductive heating is shown in Table 2 (Acar 2007).

Comparison of the widely used steam injection with the novel technique of inductive heating indicates that inductive heating method is more energy efficient and more economic as opposed to its rival. The energy consumed for heating the oil is much less as compared to the crude oil recovered from the earth.

\section{Microwaves heating}

Microwaves are high frequency waves ranging between 300 and 300,000 MHz and are called Microwaves because of their shorter wavelength. Microwaves can also be used for heating the reservoir for EOR (Sahni et al. 2000). Normally microwaves are either transmitted by a material, absorbed or reflected. In majority of the cases microwaves interact with the water molecules as they are polar in nature. Hence, when microwaves are applied these polar water molecules are set into circulatory motion and they collide speedily with other molecules with the frequency 
Table 1 Comparative analysis of conventional EOR techniques (Hammershaimb et al. 1983; Kuuskraa et al. 1983; Teknica 2001)

\begin{tabular}{llll}
\hline EOR type & $\begin{array}{l}\text { No. of } \\
\text { experiments }\end{array}$ & $\begin{array}{l}\text { Oil recovery } \\
\% \text { of ROIP }\end{array}$ & Basic principle \\
\hline Steam Drive & 26 & $30-60$ & Improvement in sweep and displacement efficiency \\
In situ combustion & 34 & $15-25$ & Improvement in sweep and displacement efficiency \\
$\mathrm{CO}_{2}$ injection & 14 & $20-30$ & Improvement in displacement efficiency \\
Surfactant flooding & 20 & $15-40$ & Improvement in sweep and displacement efficiency \\
Polymer flooding & 15 & $2-10$ & Improvement in sweep and displacement efficiency \\
Alkaline flooding & 8 & $2-5$ & Improvement in sweep and displacement efficiency \\
\hline
\end{tabular}

Table 2 Comparison of inductive heating and steam injection (Acar 2007)

\begin{tabular}{lll}
\hline Characteristics compared & $\begin{array}{l}\text { Inductive } \\
\text { heating }\end{array}$ & $\begin{array}{l}\text { Steam } \\
\text { injection }\end{array}$ \\
\hline $\begin{array}{l}\text { Water vaporization } \\
\begin{array}{l}\text { Heat value of the deposits not } \\
\text { utilized }\end{array}\end{array}$ & $\begin{array}{l}34 \mathrm{kWh} / \mathrm{t} \\
27 \mathrm{kWh} / \mathrm{t}\end{array}$ & $\begin{array}{l}34 \mathrm{kWh} / \mathrm{t} \\
675 \mathrm{kWh} / \mathrm{t}\end{array}$ \\
$\begin{array}{l}\text { Heat value of recovered oil } \\
\text { Energy return rate }\end{array}$ & $97 \mathrm{kWh} / \mathrm{t}$ & $2,295 \mathrm{kWh} / \mathrm{t}$ \\
Heating the formation & $70 \%$ & $30.6 \%$ \\
Total heat energy required & $62 \mathrm{kWh} / \mathrm{t}$ & $40 \mathrm{kWh} / \mathrm{t}$ \\
\hline
\end{tabular}

collisions equal to the frequency of applied micro waves which in result produces much heat (Okassa et al. 2010). This rise in temperature reduces the viscosity of oil and hence causes it to flow towards the production well from where it can be extracted.

Microwaves produce heat more efficiently in case of absorption inside the material but crude is not a good absorber of microwaves. To enhance the absorption power of crude oil, microwave receptors (activated carbon, iron oxide and methanol) are used which stimulate the heating process. Microwaves' heating is affected by the design of the micro wave source and the dielectric properties. Dielectric properties of material mainly depend upon the frequency of operation, temperature of the reservoir etc. Hydrocarbons mixed with sand can absorb huge amount of microwaves and hydrocarbons may get heated to achieve as high temperatures as $300-400{ }^{\circ} \mathrm{C}$ rapidly (Acar 2007). A schematic diagram for microwaves employment is provided in Fig. 4.

Studies mainly focused on three different types of reservoirs consisting of medium crude oil, shallow Lake Maracaibo heavy oil and extra heavy crude oil (Ovalles et al. 2002). Simulation results presented that microwaves heating cause the temperature of the crude oil to rise and hence the viscosity of the oil to fall which creates ease for its extraction and enhances the production of oil. Moreover, the dielectric heating can produce 10 times more heat as compared to the electricity of same power level. Microwave heating is advantageous as compared to other thermal methods because heat loss can be reduced through

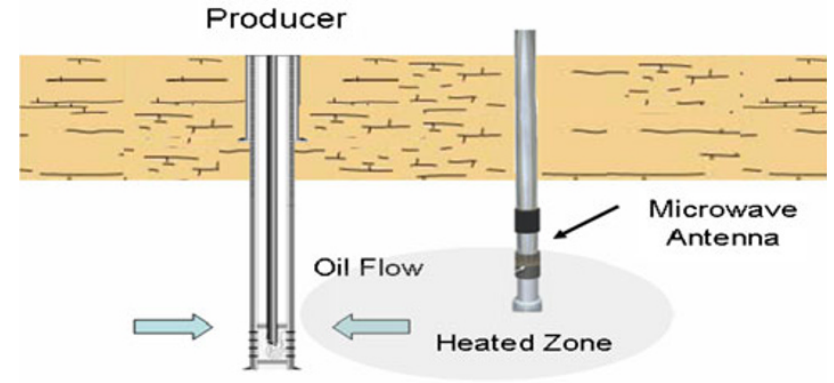

Fig. 4 Schematic view of Microwaves (Acar 2007)

controlled use of microwaves heating (Ovalles et al. 2002). Therefore, microwaves heating can be employed for EOR. Nevertheless, the penetration power of microwaves is relatively limited and depends mainly on the frequency of operation as well as the inner shape and composition of the well. A microwave cable could be a good solution for providing maximum power to the magnetron placed in specific areas of reservoir with minimum losses and attenuation (Tomberlin 1964).

Use of sonic waves for EOR

Several studies have been reported for the use of ultrasonic waves for EOR (Westermark et al. 2001; Xiao et al. 2004; Amro et al. 2006; Hamida and Babadagli 2008; Luces 2010; Mohammadian et al. 2011). Different authors have addressed different parameters of EOR e.g., change in viscosity, permeability, pressure, temperature and interfacial tension while considering different type of fluids and ultrasonic sources and concluded that use of ultrasonic waves is very well suited for EOR. It has been found that ultrasonic waves may increase the solubility of surfactants in oil which in turn will lead to decrease in interfacial tension (Hamida and Babadagli 2005, 2006). Miscible experiments have also been conducted and found that ultrasonic waves enhance the molecular diffusion at low water injection rates leading to EOR (Hamida and Babadagli 2008). Gadiev (1977) performed experimental studies of ultrasound application to oil saturated unconsolidated sand packs proving the improvement in cumulative oil recovery as well as oil production. Many field tests 
have also been performed with the application of ultrasonic waves to oil fields resulting in improved oil recovery in Texas, Siberia and California (Naderi and Babadagli 2010). From these studies, it is concluded that ultrasonic-based EOR can be applied to any type of reservoir and may also be useful in heterogeneous environment (Chen and Fairbanks 1969; Amro and Al-Homadhi 2006; Kurawle et al. 2009).

According to some authors, small oil droplets, which usually are found in the reservoir after primary recovery, may coalesce to form larger ones leading to the flow of oil which results in oil recovery (Beckham et al. 2009; Jeong et al. 2011). Ultrasonic energy is usually dissipated at the location of cracks and defects causing temperature distributions at these locations which in turn contribute towards the oil recovery. It has been found that high ultrasonic frequency is better as compared to low ultrasonic frequency as long as velocity of waves and their thermo sonic effects are concerned (Han 2003). In addition to frequency, intensity of applied ultrasound waves has also major effect on the EOR (Westermark 2001).

Different type of oil reservoirs contain crude oils of different rheology which is a critical parameter to be taken care of during oil recovery. Experiments have also been conducted to verify that ultrasonic waves have no effect on rheology of crude oil with different asphaltene levels proving that they can be suitable used for EOR (Gizem Gunal and Islam 2000). From these studies, it has been concluded that ultrasonic-based EOR can be applied to any type of reservoir and may also be useful in heterogeneous environment (Chen and Fairbanks 1969; Amro and Al-Homadhi 2006; Kurawle 2009).

Sound waves are advantageous to the conventional recovery methods in many ways. Some of them are (Amro et al. 2007):

1. There is no need for chemical stimulation which is not suitable in some cases for the reservoir rocks.

2. It can be used while the initial recovery is in progress.

3. It can also be employed to remove the filter cake especially in the horizontal wells. Filter cake is formation of all the impurities being filtered from the extracted oil and these impurities accumulate on the filter.

Usually ultrasonic-based EOR comprises the hardware parts consisting of power supply, rectifier, power amplifier, inverter, control circuitry and piezoelectric transducer. Piezoelectric transducer is used to convert the high frequency electrical signal to mechanical vibrations of the same frequency as that of applied electrical signal. A stack of piezoelectric transducers can be suitably employed to increase the amplitude of the ultrasonic stimulations created.

\section{Application of specific electrical techniques}

Different types of reservoirs exist on the earth depending upon their shape, characteristics of rocks and formation etc. Different type of electrical techniques can be applied based on characterization of different oil reservoirs as shown in Table 3. Two different models are presented for microwave heating and ultrasonic stimulations.

\section{Microwave-based EOR model}

Figure 5 presents a specific case of oil reservoir with a microwave source installed inside an injection well. Microwave generator is placed on the ground surface and provides power to the microwave antenna installed down hole. A suitable air/water cooled system is also installed inside the injection well which is supplied with cold water or cool air from the compressor pump installed on the ground surface. This is done to prevent the source from getting damaged because of excessive heat near the source. The main advantage of the microwave-based EOR is that source can suitably be employed near the target area.

\section{Ultrasonic-based EOR model}

Similarly Fig. 6 provides an over view of a proposed fieldscale ultrasonic-based device for EOR under the constraint to recover a specific quantity of oil from the reservoir. In this setup electrical part of the setup is placed on the ground surface while ultrasonic part is installed inside the injection well. Rectifier converts the AC voltage to DC which in turn is amplified by the power amplifier. High frequency inverter chops the high voltage DC signal converting it into high frequency square waves which are then supplied to the piezoelectric transducers installed within the injection well. Ultrasonic transducers generate the ultrasonic stimulations at the frequency of applied square wave signal. Since these mechanical vibrations generated by ultrasonic transducer are low in amplitude, an ultrasonic booster is coupled to the transducer to amplify the mechanical vibrations. Finally an ultrasonic horn couples these high frequency and high amplitude ultrasonic stimulations to the oil reservoir by proper impedance matching. Analog switches are installed inside the injection well and controlled from the control circuit in order to switch on or switch off a specific arrangement and number of ultrasonic transducers.

\section{Electrical EOR vs. conventional EOR}

Electrical EOR (EEOR) has many advantages over Conventional EOR, some of them are listed below: 
Table 3 Comparison between different electrical EOR techniques

\begin{tabular}{|c|c|c|}
\hline EEOR type & Suitability & Limitations \\
\hline Induction heating & $\begin{array}{l}\text { Suitable especially in the presence of thief zones or in the } \\
\text { reservoirs not suitable for other thermal EOR techniques } \\
\text { Different set of low and high frequency electrical currents can be } \\
\text { used according to the requirements } \\
\text { Reservoirs having low in situ water saturation }\end{array}$ & Can only be applied to heat the near well bore areas \\
\hline $\begin{array}{l}\text { Low frequency electric } \\
\text { heating (Joule } \\
\text { heating) }\end{array}$ & $\begin{array}{l}\text { Maximum power transfer may get limited in some field } \\
\text { applications because of hot spots occurring near the ends of } \\
\text { electrodes } \\
\text { Based on energy supplied, it can be alternative of steam injection } \\
\text { Reservoirs comprising of high permeability streaks or fractures }\end{array}$ & $\begin{array}{l}\text { Temperature should be maintained below the } \\
\text { boiling point of water in order to maintain } \\
\text { continuity } \\
\text { Corrosion may occur on the electrodes in high salt } \\
\text { concentration reservoir }\end{array}$ \\
\hline Microwave heating & $\begin{array}{l}\text { Suitable for reservoirs containing heavy oil } \\
\text { Mostly applicable to reservoirs having the target area directly } \\
\text { exposed to microwaves without any hurdles }\end{array}$ & $\begin{array}{l}\text { Require shut down of production } \\
\text { Penetration depth of high frequency is limited } \\
\text { Source may get damaged because of extensive heat } \\
\text { production } \\
\text { Not applicable to water flooded reservoirs }\end{array}$ \\
\hline Ultrasonic stimulations & $\begin{array}{l}\text { Suitable for reservoirs with high water saturation or depleted } \\
\text { reservoirs } \\
\text { Suitable for the reservoir having heavy oil lying behind water }\end{array}$ & $\begin{array}{l}\text { Size of ultrasonic vibrator is limited by the } \\
\text { diameter of injection well } \\
\text { Not suitable for unconsolidated formations with } \\
\text { compressive strength of less than } 150 \mathrm{psi} \\
\text { Not suitable with a slurry mixture of sand and } \\
\text { water }\end{array}$ \\
\hline
\end{tabular}

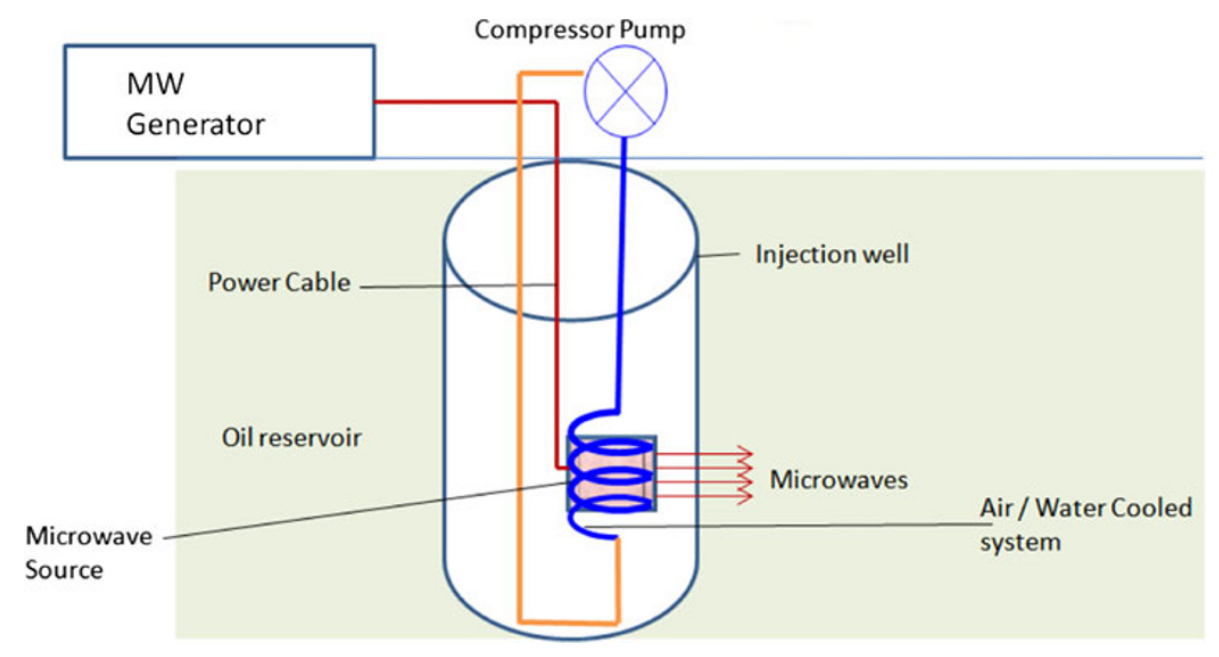

Fig. 5 A microwave-based EOR setup

- In conventional EOR, external materials e.g., chemicals, gases, steam or water are injected into the reservoir while in case of Electrical EOR is purely based upon the voltage and frequency without any requirements for chemical, steam or gas injection.

- Waiting time to see the results for electrical EOR is much less as compared to conventional EOR techniques.

- Employing the electrical techniques, electrical or electromagnetic heat energy/mechanical vibrations can be directed precisely towards the target area proving these techniques as efficient and cost effective as opposed to conventional EOR.

- Geology or characterization of the reservoir is not affected by employing electrical techniques.

- No storage and supply of chemicals or other fluids is required for electrical procedures as opposed to conventional techniques. This latest leads to the suitability of electrical methods for both onshore and off shore reservoirs.

- Electrical EOR methods also do not need dumping of any waste material, e.g., chemicals, etc., and hence are environment friendly. 


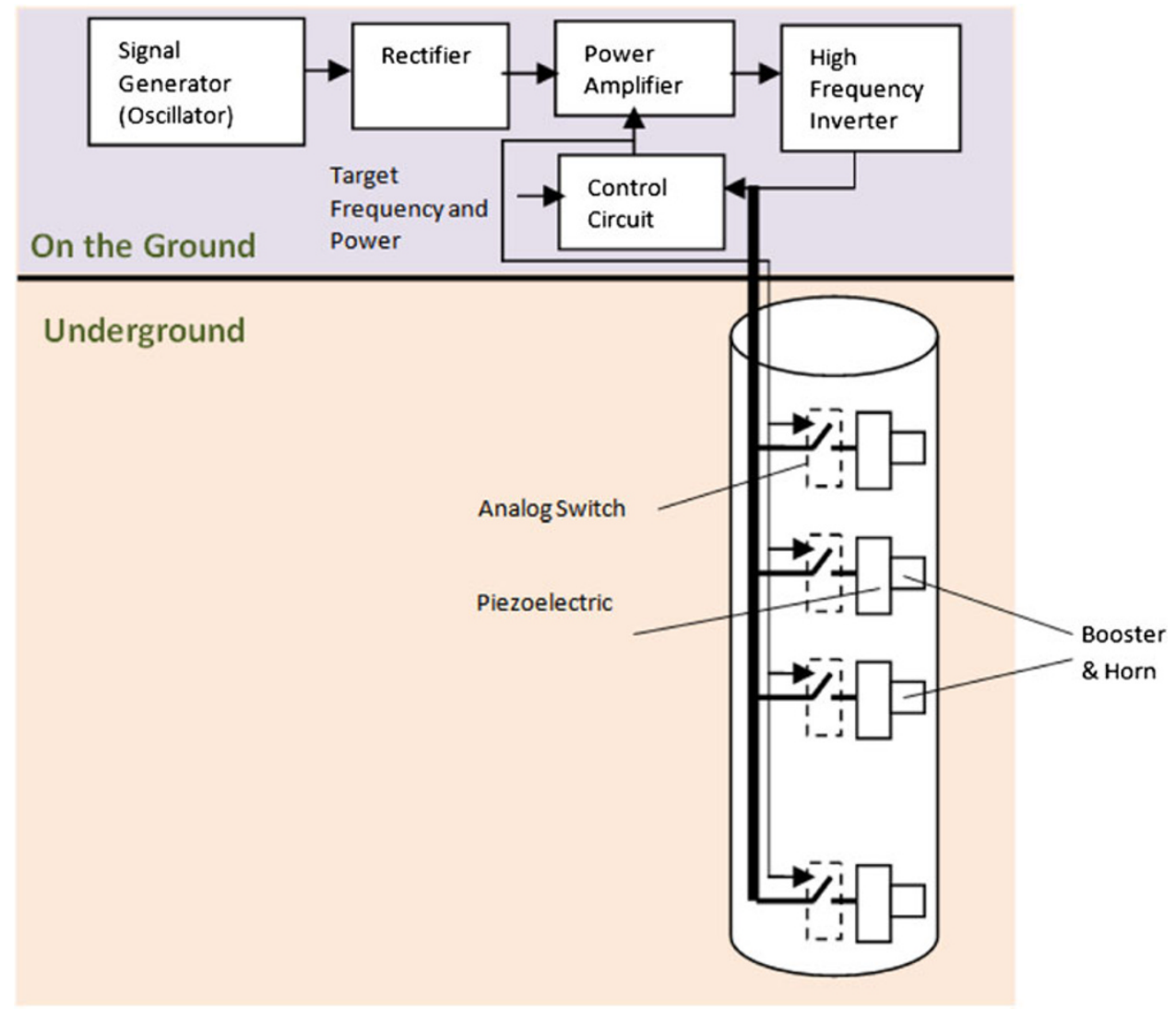

Fig. 6 An ultrasonic waves-based EOR setup

Microwaves EOR with added advantages

Microwaves EOR is the optimum case of EEOR in many cases and helps to extract the best possible quantity of oil within less time as compared to other EEOR methods. It is because of the dielectric heating effect of Microwaves, when microwaves are applied to a material medium, it directly interacts with the polar molecules. Since the frequency of applied microwaves is very high, they produce electric and magnetic fields alternating at microwaves frequency. When these alternating electric and magnetic fields interact with the polar molecules, these polar molecules are set into vibrations at the frequency of applied microwaves. Because of this change in polarity, vibrations and collisions with the other molecules at such a high frequency, a great deal of energy is produces which helps in raising the temperature of the environment (Okassa et al. 2010). When microwaves are applied to the hydrocarbons reservoir, this increase in temperature helps in reducing the viscosity of oil and enabling the oil to flow towards the production well from where it can be extracted.

Microwaves produce heat more efficiently in the case of absorption inside the material but crude is not a good absorber of microwaves. To enhance the absorption power of crude oil microwave receptors (activated carbon, iron oxide and methanol) can be used which stimulate the heating process. Microwave heating is affected by the design of the micro wave source and the dielectric properties. Dielectric properties of material mainly depend upon the frequency of operation, temperature of the reservoir etc. Hydrocarbons mixed with sand can absorb huge amount of microwaves and hydrocarbons may get heated to achieve as high temperatures as $300-400{ }^{\circ} \mathrm{C}$ rapidly (Acar 2007).

Ovalles et al. (2002) presented discussions on three different types of reservoirs consisting of medium crude oil, shallow lake Maracaibo heavy oil and extra heavy crude oil. Simulation results presented that Microwaves heating cause the temperature of the crude oil to rise and hence the viscosity of the oil to fall which creates ease for its extraction and enhances the production of oil. Moreover, the dielectric heating can produce 10 times more heat as compared to the electricity of same power level. Microwave heating is advantageous as compared to other thermal methods because heat loss can be reduced through controlled use of microwaves heating. Therefore, microwaves are a good candidate for use in EOR with the only limitation of penetration of microwaves which depends mainly on the operational frequency as well as the inner characterization of the wells. Microwaves cannot pass 
through water and they can only travel in line of sight. At higher frequency the attenuation of microwaves increases.

A solution to these problems can be employment of microwave source close to the target area in order to heat it without losing energy and efficiently using all the energy to heat up the reservoir.

\section{Conclusion}

Electrical EOR is the best alternative of the conventional EOR in terms of utilizing the energy efficiently in heating a specific part of the reservoir, low cost, no environmental impacts in terms of effects on the geology of the reservoir and hence the area. In addition EEOR has no need for production arrangement, transportation and storage of specific reactants. In addition EEOR provides an increase in the production of oil as compared to its counterpart the conventional EOR. Switching technique between different EEOR processes can also be employed based on the need. Microwaves are an ideal candidate from EEOR processes in many application areas with reduced cost and focused heating effects. Different schemes of electrical-based EOR are presented and a comparison is also provided in terms of advantages on the conventional EOR techniques. In addition, two basic oil field models have also been presented and discussed for two of the electrical-based techniques named as microwave heating and ultrasonic stimulations.

Electrical EOR has also some limitations as other conventional techniques do. These include non-uniform heating of reservoir especially most of the energy and heat is concentrated near the well bore region. Some cases are only applicable in the presence of brine e.g., resistive or joule heating. Similarly electrodes also suffer from the corrosion and this issue needs to be resolved. Similarly microwaves only travel in line of sight and presence of any hurdle in between the source and target may attenuate them resulting in energy loss.

Future work may focus on the areas of control feedback for providing the real time temperature and pressure conditions inside the reservoir during the heating process and based on the results, the process should be boosted or stopped. Similarly, in terms of switching between different EEOR processes, the conditions of the reservoir should be investigated and based on the results a selection from different available EEOR processes should be done, which can provide an optimum recovery for the conditions of the reservoir. It can also be done using a control feedback loop which can analyze the conditions and can decide about the best suited method and adopt it based on the results. Similarly the decision regarding location for employment of electrical sources inside the well should be taken for the best possible recovery, a feedback loop should be developed which can calculate the desired position and basing upon the results can adjust the position of the heaters accordingly.

Open Access This article is distributed under the terms of the Creative Commons Attribution License which permits any use, distribution, and reproduction in any medium, provided the original author(s) and the source are credited.

\section{References}

Acar Ç (2007) Enhancing Petroleum Recovery from Heavy Oil Fields by Microwave Heating. Masters Dissertation, Middle East Technical University, Ankara, Turkey

Akfhampour KH (1985). A novel approach to solving downhole fluid flow problems by use of an electric heating system. In: IEEE IAS Petroleum and Chemical Industry Committee Houston, $\mathrm{p} 12$

Amba S, Chilingar G et al (1964) Use of direct electrical current for increasing the flow rate of reservoir fluid during petroleum recovery. J Can Pet Technol 3(1):8-14

Amro MM, Al-Homadhi ES (2006) Enhanced oil recovery using sound wave stimulation. Final Research Report. Riyadh, Saudi Arabia, King Saud University. 53/426

Amro M, Al Mobarky M, et al. (2007) Improved oil recovery by application of sound waves to water flooding. In: SPE Middle East oil and gas show and conference, Kingdom of Bahrain

Andrei M, Simoni MD, et al. (2010) Enhanced oil recovery with $\mathrm{CO}_{2}$ capture and sequestration. Congress Paper, Eni, Italy, p 20

Bailey S, Kenney T, et al. (2001) Microbial enhanced oil recovery: diverse successful applications of biotechnology in the oil field. In: SPE Asia Pacific improved oil recovery conference, Kuala Lumpur, Malaysia

Baptist OC (1960) Oil recovery and formation damage in Permafrost, Umiat Field, Alaska, US Department of the Interior, Bureau of Mines

Beckham RE, Abdel-Fattah AI et al (2009) Mobilization of colloidal particles by low-frequency dynamic stress stimulation. Langmuir 26(1):19-27

Bruninga JH (1957). Electrolytically Promoting the flow of Oil from a Well, U.S Patents. 2799641

Butt G (2001). Oil and Gas in the UAE. United Arab Emirates. A new perspective. Trident Press, London pp 231-248

Carrizales M, Lake LW (2009) Two-Dimensional COMSOL Simulation of Heavy-Oil Recovery by Electromagnetic Heating. COMSOL Conference, Boston

Carter LD (2011). Enhanced oil recovery \& CCS. Palo Alto., United States carbon Sequestration Council

Chakma A, Jha K (1992) Heavy-oil recovery from thin pay zones by electromagnetic heating. In: Annual technical conference and exhibition, Washington DC

Chen W, Fairbanks H (1969) Recovery of oil with the aid of ultrasonics. IEEE Trans Sonics Ultrason 16(2):65-67

Chilingar GV, Chang KS et al (1968) Possible use of direct electrical current for augmenting reservoir energy during petroleum production. The Compass 45(4):272-285

Crowson FL (1971). Method and Apparatus for secondary recovery of Oil, US Patents. 3605888

Fisher ST (2007) Processing of solid fossil-fuel deposits by electrical induction heating. IEEE Trans Ind Elect Control Instrum 27(1):19-26

Gadiev S (1977). Use of vibrations in oil production (Ispol'zovaniye vibratsii v dobyche nefti), Nedra Press 
George VC, Walter W et al (1997) Present and potential applications of electromagnetic heating in the in situ recovery of oil. Energy Sources 19(2):129-146

Gill WG (1970) Method and apparatus for secondary recovery of Oil, US Patents. 3507330

Gizem Gunal O, Islam M (2000) Alteration of asphaltic crude rheology with electromagnetic and ultrasonic irradiation. J Petrol Sci Eng 26(1):263-272

Green DW, Willhite GP (1998) Enhanced oil recovery. Richardson, Texas, Society of Petroleum Engineers

Hamida T, Babadagli T (2005) Capillary interaction of different oleic and aqueous phases between matrix and fracture under ultrasonic waves. SPE Europec/EAGE Annual Conference, Madrid, Spain

Hamida T, Babadagli T (2006) Investigations on capillary and viscous displacement under ultrasonic waves. J Can Pet Technol. 45(2): 16-19

Hamida T, Babadagli T (2008) Displacement of oil by different interfacial tension fluids under ultrasonic waves. Colloids Surf A 316(1-3):176-189

Hammershaimb E, Kuuskraa V, et al. (1983) Recovery efficiency of enhanced oil recovery methods: a review of significant field tests. In: SPE annual technical conference and exhibition, California

Han X (2003) Frequency dependence of the thermosonic effect. Rev Sci Instrum 74:414

Harvey A, Arnold M et al (1979) Selective electric reservoir heating. J Can Pet Technol 18(3):47-57

Hascakir B, Babadagli T, et al. (2008). Experimental and numerical modeling of heavy-oil recovery by electrical heating. In: SPE international thermal operations and heavy oil symposium, Calgary, Alberta, SPE

Islam MR, Chilingarian GV (1995) A new technique for recovering heavy oil and tar sands. Sci Iran 2(1):15-28

Jeong C, Kallivokas L, et al. (2011) Maximization of oil mobility within a hydrocarbon reservoir for elastic wave-based enhanced oil recovery. In: SPE annual technical conference and exhibition, Denver, Colorado

Kurawle I, Kaul M, et al. (2009). Seismic EOR? The optimization of aging waterflood reservoirs. In: SPE offshore Europe conference, Aberdeen, UK

Kuuskraa VA, Stosur G, et al. (1983) RP 13 The efficiency of enhanced oil recovery techniques: a review of significant field tests. In: 11th world petroleum congress, London

Luces MAR (2010) Viscoelastic Properties of Heavy Oil. Ph.D Thesis, University of Houston

Mohammadian E, Shirazi MA, et al. (2011) Enhancing oil recovery through application of ultrasonic assisted waterflooding. In: SPE Asia Pacific oil and gas conference and exhibition, Jakarta, Indonesia
Naderi K, Babadagli T (2010) Influence of intensity and frequency of ultrasonic waves on capillary interaction and oil recovery from different rock types. Ultrason Sonochem 17(3):500-508

Okassa F, Godi A, et al. (2010) A nonconventional EOR technology using RF/MW heating coupled with a new patented well/ reservoir interface. In: SPE annual technical conference and exhibition, Florence, Italy., SPE

Oliveira H, Barillas JL, et al. (2009) Energetic optimization to heavy oil recovery by electromagnetic resistive heating (ERH). In: SPE Latin American and Caribbean petroleum engineering conference, Colombia

Ovalles C, Fonseca A, et al. (2002). Opportunities of downhole dielectric heating in Venezuela: three case studies involving medium, heavy and extra-heavy crude oil reservoirs. In: SPE international thermal operations and heavy oil symposium and international horizontal well technology Conference, Calgary, Alberta, Canada

Saadawi H, Johns A, et al. (2011). A study to evaluate the impact of $\mathrm{CO}_{2}$-EOR on existing oil field facilities. In: SPE symposium on projects and facilities challenges at METS Doha, Qatar, SPE

Sahni A, Kumar M, et al. (2000). Electromagnetic heating methods for heavy oil reservoirs. In: SPE/AAPG Western regional meeting long beach, SPE, California

Sarapuu E (1957). Method of underground electrolinking and electrocarbonizaion of mineral fuels, US Patenets. 2795279

Sierra R, Tripathy B, et al. (2001). Promising progress in field application of reservoir electrical heating methods. In: SPE Symposium on international thermal operations and heavy oil Margarita, SPE, Venezuela

Stevens S, Kuuskraa VA et al. (1998) Enhanced oil recovery scoping study, Final Report. Palo Alto, Electric Power Research Institute

Teknica (2001). Enhanced Oil Recovery. T. P. s. Ltd. Albarta, Canada, Enhanced Oil Recovery by teknica, p 352

Tomberlin BM (1964) Electrical energy to subsurface, Google Patents. US Patent No.3133592

Vermeulen F, McGee B (2000) In Situ Electromagnetic Heating for Hydrocarbon Recovery and Environmental Remediation. J Can Pet Technol 39(8):25-29

Westermark R, Brett J, et al. (2001). Enhanced oil recovery with downhole vibration stimulation. In: SPE production and operations symposium, Oklahoma city, Oklahoma

Workman PE (1930) Method of recovering and increasing the production of oil, US Patents. 1784214

Xiao G, Zhimin D, et al. (2004). High frequency vibration recovery enhancement technology in the heavy oil fields of China. In: SPE International Thermal Operations and Heavy Oil Symposium and Western Regional Meeting, Bakersfield, California, 16-18 March 2004

Zhou Z, Gunter W et al (1996) Effect of clay swelling on reservoir quality. J Can Pet Technol 35(7):19 